\title{
Assessing Teachers' Attitude toward ICT Diffusion in Rural Primary School of Thailand
}

\author{
Nopparat Meeplat
}

\begin{abstract}
The purpose of this paper is to present a research study that assesses the teachers' satisfaction in the primary school located in the rural area of Thailand. The study explores the ICT diffusion in rural primary school and assesses the teachers' attitude from using ICT in the classroom. This study used quantitative data. Data were collected from teachers in the primary school from rural area of Nakhon Si Thammarat. The results found that there is significant relationship between teachers' attitude level toward diffusion of ICT which can increase teachers' competency. The teachers were satisfied of using ICT in the classroom and they suggested that the government should provide training courses for all teachers who use ICT in the classroom.
\end{abstract}

Index Terms-Diffusion ICT, teachers' competency, teachers' attitude, teachers' satisfaction.

\section{INTRODUCTION}

The rapid development in information and communication technologies (ICTs) has led to a technical disparity. What exists today cannot only be confined to computer or Internet use; but that it also refers to infrastructural problems, like the accessibility to fixed phone line and mobile phones [1] Ever since the growth of ICT since the last two decades, there have been numerous studies on modelling and diffusion of ICT innovation [2]

Currently, Information Communication and Technology is important for social economic and education that consists of primary school, secondary school and higher education. Therefore, this study emphasizes on the attitude of teachers who use the ICT for teaching and learning in primary school in southern of Thailand.

According to Roger [2] diffusion is the process by which an innovation is communicated through certain channels over time among the member of a social system. Diffusion is special types of communication concerned with the spread of messages that are perceived as new ideas. There are four main elements in the diffusion of new ideas, that is, innovation, communication channels, time and the social system. Innovation is an idea, practice or object that is perceived as new by an individual or other unit of adoption. The communication is the process by which participants create and share information with one another in order to reach a mutual understanding. The time dimension is involved in diffusion in three ways, which is, innovation-decisions process, innovativeness of an

Manuscript received March 25, 2014; revised May 25, 2014

Nopparat Meeplat is with the Faculty of Educaiton in Nakhon Sri Thammarat Rajabhat University, Thailand (e-mail: dewmemory@hotmail.com). individual or other unit of adoption and rate of adoption. The social system is defined as a set of interrelated units that are engaged in joint problem solving to accomplish a common goal. The social system constitutes a boundary within which an innovation diffuses, and how the system's social structure affects diffusion has been studied. The social system focuses on the opinion, leadership, attitude, knowledge and the behavior of people who are using ICT [2]. Some authors revised the definitions of the DOI as it seeks to explain how innovations are taken up in a population. An innovation is an idea, behavior, or object that is perceived as new by its audience [3]. The main objective of the diffusion model (DOI) is to describe a pattern of spread of innovation among potential adopters in terms of a mathematical function of time [4].

However, the problem that occurs from the teachers in primary school is about the way of using ICT for teaching and learning in the classroom because some school the teachers who responsibility about computer subjects they didn't related to computer major. Thus, the teachers read computer books and teach but there is not enough knowledge for teaching. Therefore, the government provides training courses for teachers who are not graduated in computer major. However, the problems still occur in primary school.

This paper tries to explore the teachers 'attitude toward diffusion of ICT in rural primary school. The study is also assessing the teachers' altitude and teachers' competency from using ICT. The research questions driving this study are as follow:

1) Can teachers' attitude towards the diffusion of ICT influence his/her level of competency?

2) Are competent teachers able to teach efficiently?

3) Can the diffusion of ICT in the classroom increase teachers' satisfaction?

The research questions would find answers to teachers' attitude on diffusion of ICT, its effect on the level of competency, efficiency in teaching and increased teachers' satisfaction. There are five parts to this paper. Firstly, in the introduction, a brief description of ICT diffusion is given. This is followed by the problem statement and the objectives of the study. Secondly, the review of literature describes the ICT diffusion, ICT in education in Thailand and teachers' satisfaction. Thirdly, the research method is presented along with the data analysis technique. Fourthly, a brief discussion and summary of findings are presented. Finally, the paper concludes with recommendation for future research.

\section{A. Problem Statement}

In Thailand, the school is being transformed into a centre for the diffusion of technology, specifically in poor communities. Much of the technological innovations that are 
not available either at home or in other community spaces are accessible through the school. Therefore, all teachers in rural primary schools of Thailand need to learn how to use computer and how to teach the children by using computer as tools in the classroom. So it is difficult to diffuse ICT in rural primary schools because they have a long period of teaching amounting to 18 hours per day [5] hence more time is needed for training in ICT. This phenomenon can be viewed as a big problem for Thai education especially in rural area. In addition, studies have identified the wide gaps in the use of ICTs between urban and rural primary schools, with insufficient and inadequate computer and other ICT tools such as network tools, poor internet connectivity, inadequate manpower, and no coherent ICT policy framework [6]. Thus this study would like to assess the success factors of ICT diffusion of innovation in the rural primary schools in Thailand and the teachers' satisfaction of using ICT in rural primary school.

\section{B. Objective of the Research}

Based on the problems statement there are two objectives as follow:

1) To explore the relationship between teachers' attitude and competency with ICT diffusion in rural primary school; and

2) To assess the teachers 'satisfaction from using ICT in the classroom.

\section{LITERATURE REVIEW}

\section{A. ICT Diffusion}

Currently, the ICT innovations are integrating into teaching activities in the education system. Since, innovation is the key to success in every sphere of life, changes are happening in everyday life and one has to adapt to new situations and challenges.

The education system can apply innovation into the form of diffusion of ICT innovation. The education system can gradually dig out innovation acceptance enablers, under reasonable legal agreements, and help teachers reproduce their own version of digital teaching materials through education resource sharing platforms. This mechanism will increase the popularity of integrating ICT innovation into teaching activities and make it operate continuously [7].

Ref. [6] states that diffusion of ICT innovation presents information which is important for decision makers to define education's potential students, service area, core competencies and other aspects necessary for an integrated ICT adoption strategy. Diffusion of ICT innovation is most important for learning and growth of people in the real world. Since ICTs have been greatly empowered people believe that they can compete in the global knowledge-based economy because they know that their knowledge, ideas, culture and passions are as valuable as any in the world [8].

In addition, diffusion of ICT innovation in the education system has been of paramount important. It is a contributing factor to meaningful participation in the knowledge society in which education forms the fundamental element [9].

In rural contexts, many people see technology as an opportunity to overcome the barriers of geographic isolation experienced by these kinds of communities, offering them new opportunities for education and employment, and access to knowledge and communication with other people. One potential opportunity for addressing weakness of teaching and pedagogy is to augment educational delivery with appropriate use of information and communication [10].

\section{B. ICTs in Thai Educational System}

In the face of global social and economic challenges, many governments around the world are looking to reform their educational system to prepare students for the $21^{\text {st }}$ century. Similarly, Thai government focuses on the use of ICT to improve access to education and the outcome is seen as central to the advancement of Thai society and has been enshrined in the education of Thailand. Thai government has provided the two visions of education for Thai people. The first vision of education for Thailand is enabling future education with ICT [11].

What this mean is that ICT is crucial to the development of all Thai citizens and in this regards requires careful and serious consideration of the issues surrounding its development, introduction and use [12].

The second vision of education for Thai people is the implementation of technology in education. It is believed that learning technologies will improve access to educational opportunities and improve outcomes for Thai students in the $21^{\text {st }}$ century. A key aim is to transform Thai society into a learning society, able to take advantage of the opportunities available by connecting with the global knowledge economy, while gaining a greater understanding and appreciation of Thai culture and society. The learner is at the centre of these education reforms [13].

\section{Teachers' Competency}

Today, teachers need to improve knowledge and skills to enhance, improve and explore their teaching practices. Therefore, many of the studies on competencies of teacher emphasizes on the teaching role of the teachers in the classroom. Competencies means knowledge, skills, attitude, values, motivations and beliefs people need in order to be successful in the jobs. ICT competencies are based on using ICT as tools for transferring knowledge. Therefore, this study would like to investigate that teachers' competency can be related to teaching efficiency [11].

\section{RESEARCH METHODOLOGY}

\section{A. Research Design and Instrument}

The study use quantitative method which survey questionnaire. The questionnaire consists of three parts. First part is the demographic data, second is about the attitude of using ICT in education such as teachers' anxiety, teachers' confidence, and ICT benefits. The third part is about the competency of using ICT as tools for teaching in the classroom and use ICT as a supplementary for teaching in the classroom. These variables were tested to be reliable as illustrated by their Cronbach alpha values of between .700 and .800 respectively.

\section{B. Participants and Sampling Technique}

The sample population of this study $(n=)$, selected are the 
teachers from rural primary schools in Nakhon Si Thammarat Province Thailand. The study selected only the schools that are located in rural area. Each school has only one computer lab. Altogether 11 schools were chosen.

\section{Variable of This Study}

The variable of this study is based on the diffusion of ICT in primary school, the attitude of teachers when they used ICT, the teachers' competency and the last is on teachers' satisfaction.

\section{RESULTS}

To explore the teachers' attitude, competency and satisfaction, the Pearson's product-moment correlation coefficient has been conducted for the bivariate correlation analysis. Table I illustrates the education level of participants.

\begin{tabular}{c|c|c}
\multicolumn{3}{c}{ TABLE I: EDUCATION LEVEL } \\
\hline Education level & Total & Percentages \\
\hline Certificate & 1 & 1.8 \\
Bachelor degree & 40 & 81.5 \\
Master degree & 5 & 16.7 \\
\hline
\end{tabular}

There are 55 participants, with $79.6 \%$ holding bachelor degrees, $17.9 \%$ received master degrees and $1.8 \%$ has certificates.

\begin{tabular}{ccc}
\multicolumn{3}{c}{ TABLE II: EXPERIENCES OF TEACHING } \\
\hline Experiences & Total & Percentage \\
\hline $1-5$ & 14 & 23.2 \\
$6-10$ & 17 & 30.4 \\
$11-15$ year & 10 & 17.9 \\
$>$ 16 year & 14 & 25 \\
\hline
\end{tabular}

Table II illustrates the experience as a teacher, 25\% have experience of teaching more than 16 years, while $17.9 \%$ have experience in $11-15$ years. In addition, $30.4 \%$ are $6-10$ years and $23.2 \%$ have $1-5$ years of teaching.

This study analyzed the findings based on the following hypotheses.

Hypothesis 1: Teachers' attitude towards diffusion of ICT can increase teachers' competency

\begin{tabular}{llllll}
\multicolumn{7}{c}{ TABLE III: MODEL SUMMARY OF RESULTS } \\
\hline Model & Predictors & R & R2 & F & Sig.F \\
\hline 1 & Teachers'attitude & .543 & .295 & 22.15 & .000 \\
\hline \multicolumn{7}{c}{ TABLE IV: MODEL SUMMARY OF RESULTS } \\
\cline { 2 - 6 } & \multicolumn{7}{c}{ Model } & Predictors & R & R2 & F & Sig.F \\
\hline 1 & Teachers & .581 & .338 & 27.049 & .000 \\
& 'competency & & & & \\
\hline
\end{tabular}

Table III illustrates the teachers' attitude as ICT can increase teachers' competency. Hypothesis 1 examined the relationship between teachers 'attitude toward diffusion ICT and teachers' competency. The result showed that the teachers' attitude is positively correlated to teachers' competency toward diffusion ICT in rural primary school. The relationship is significant at the level 0.01 level. This hypothesis is supported.

Hypothesis 2: Teachers' competency can increase the teaching efficiency of the teachers.

Table V illustrates teachers' competency that can increase the teaching efficiency of the teachers after using ICT. This hypothesis explains the relationship between teachers' competency and the teaching efficiency. The relationship is significant at the 0.01 level. This hypothesis is supported.

\section{DISCUSSION}

The results indicate that teachers welcome the diffusion of ICT in rural primary schools. This means that teachers who are able to use ICT efficiently are able to perform better by teaching more efficiently. They think that ICT can increase the learning outcomes. The increased in the level of satisfaction as a result of the ICT diffusion means teachers are satisfied with ICT use in the classroom characterized by ease of use of the appropriate hardware and software to support teaching and learning. Hence it is important that proper and adequate training be given to teachers to increase their proficiency in ICT.

For the relationship between teachers' attitude towards diffusion of ICT and teachers' competency the result indicates positive relationship between teachers' attitude and teachers' competency. This implies that the competency level of teachers can significantly be increased through the diffusion of ICT in the classroom. This is consistent with [12] [14], [15] who state that teachers who have positive attitudes toward ICT can improve their teaching competency.

The relationship between teachers' competency and teaching efficiency indicates a positive relationship. This implies that competent teachers who make use of ICT are able to teach more efficiently. Hence ICT can be seen as a tool that can support teaching and learning in the classroom, which in turn able to increase the competency level of teachers. Similarly as stated by [16], [17] that ICT can increase teachers' competency.

The results also found that the diffusion ICT in rural primary school can make the teachers satisfied and happy when using ICT. Ref. [18] reported that teachers tend to be more satisfied when using ICT in higher education.

\section{CONCLUSION}

This study has made an attempt to assess the teachers' competency, teachers' attitude and teachers' satisfaction as a result of the diffusion of ICT as an innovative tool for teaching and learning. The study found that all hypotheses were supported and are significantly related to ICT diffusion in rural primary schools. However, further research will be needed to cover other rural areas as the sample used in this study is considered small to represent the population of rural Thai primary schools. For the next research will be study about all population of primary school and secondary school.

\section{REFERENCES}

[1] M. L. M Fong, "Digital divide: The case of developing countries," Informing Science and Information Technology, vol. 6, no. 2, January, 21, 2009.

[2] F. M. Rogers. (1997). Diffusion of Innovation Theory. [Online]. Available: http://www.google.comDOI 
[3] L. Robinson. (2009). A summary of Diffusion of Innovation. [Online]. Available: http://www.enablingchange.com.au

[4] K. Arkadiusz and K. Tomasz. (2010). Modelling of Innovation diffusion, Operation research. [Online]. Available: http://www.enablingchange.com.au.

[5] F. W. K. Amenyedzi, M. N. Lariey, and B. M. Dzomeku, "The use of computers and internet as supplementary source of educational material: A case study of the senior high schools in the tema metropolis in Ghana," Comptempory Educational Technology, 2014, vol. 2, no. 2, pp. 151-162.

[6] N. Vivekananthamoorthy, S. Sankar, R. Siva, and S. Sharmile, "New paradigms for innovation in teaching and learning process," in Proc. 2009 7th International Conference on ICT and knowledge Engineering, pp. 94-99, 2009.

[7] H. O. Al-Mobaideen, "ICT diffusion in Jordanian Universities," in Proc. European and Mediterranean conference on Information Systems 2009, Crowne Plaza Hotel, ACM, vol. 3, pp. 5-28, 2009.

[8] InfoDEV. (2010). ICT in School Education (Primary and Secondary school. [Online]. Available: http://google.com

[9] A. I. Jimenez-Zarco, M. R. P. Marinez-Ruiz, and M. R. liamas-Alonso, "Analysis of ICTs opportunities on firm's success: An innovation process," Problems and Perspectives in Management, vol. 4, no. 4, pp 84-94, 2009.

[10] I. Anderson and M. Rory, "Disruptive pedagogies and technologies in universities," Educational Technology \& Society, pp. 380-389, vol, 15 , no. 4,2012

[11] Thailand ICT Master Plan 011-2013. (January 21, 2014). [Online]. Available:

http://unapcict.org/ecohub/resources/thailand-information-and-com munication-technology-master-plan-2002-2006.

[12] Ministry of Education. (January 21, 2014). [Online]. Available: http://th.foursquare.com

[13] J. Ainley, P. Arthur, P. Macklin, and B. Righy, Capacity building of Thai learning technologies 2010, 2010.
[14] C. Bulent, "A study on science teachers' attitudes toward Information and communication technologies in education," The Turkish Online Journal of Educational Technology, ISSN: 1303-6521, vol. 8, no. 2, April 2009.

[15] UNESCO. (September 24, 2013). UNESCO Global Report: Opening New Avenues for Empowerment ICTs to Access Information and Knowledge for Persons with Disabilities. [Online]. Available: www.unescobkk.org/culture/wh/asia...2000.../2013ha1/

[16] J. Ainley, P. Arthur, P. Macklin, and B. Righy, "Capacity building of Thai learning technologies 2010," 2002.

[17] A. S. A. Lawrence and K. Veena. (2012). Improving teacher competency through ICT. [Online]. Available: http://www.Academia.edu/1462066/ICT_andTeacher competencies

[18] V. Mehra and N. Z. Far, "A Scale to Measure University teachers' attitude toward ICT," International Journal of Teacher Educational Research (IJTER). vol. 2, no. 7, July, 2013.

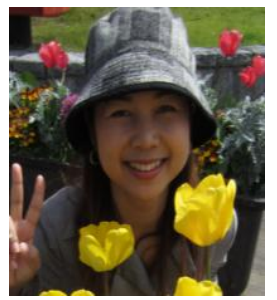

Nopparat Meeplat was born in 1977, in Songkhla province of Thailand. She graduated bachelor degree of statistical science, Kingdegree from King Mongkuts University of Technology Noth Bangkok. She received master of information technology from Universiti Utara Malaysia in 2006. Currently, she is studying doctoral degree in Information Technology at Universiti Utara Malaysia (UUM).

She is a lecturer at computer educaiton program of faculty of Educaiton in Nakhon Sri Thammarat Rajabhat University, Thailand. She was presented a paper of Rural ICT development of Thailand at Rural ICT conference in Malaysia in 2010. Her last presentation was about ICT development in primary school at 2013 e-Case \& e-Technology in Kitakhyshu, Japan, 2013. 